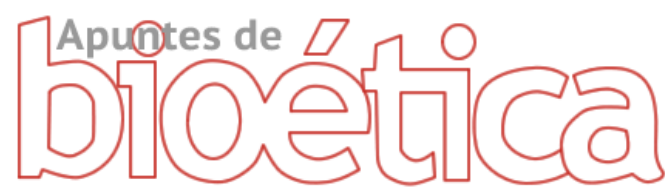

https://doi.org/10.35383/apuntes.v1i1.195

\title{
Tendencias en los proyectos de leyes del 2018, para regular las técnicas de reproducción artificial en el Perú
}

\author{
Olga Mercedes Helfer Llerena de Tapia ${ }^{1}$, Sergio Carlos Baltazar Tapia Tapia ${ }^{2}$
}

\section{INFORMACIÓN DEL ARTÍCULO RESUMEN}

Recibido el 28 de setiembre de 2018 Aceptado el 21 de noviembre de 2018

\section{Palabras claves:}

Bioética

Biojurídica

Técnicas de reproducción artificial (TRA)

Biotecnologías

Concepción

Anidación

Embrión humano

Pre-embrión

Maternidad subrogada

Crioconservación

Selección embrionaria

Reducción embrionaria
Las técnicas de producción artificial (TRA) generan vida humana de modo artificial, es decir sin observar el proceso natural que es la unión sexual entre varón y mujer. Por lo que establecer criterios bioéticos y biojurídicos lo estimamos oportuno en las circunstancias que se debatirá la modificación de la norma sobre las TRA en el Perú. Para tal fin, con la presente investigación nos proponemos analizar el contenido y consecuencias de las TRA, analizar el vigente artículo $7^{\circ}$ de la Ley N ${ }^{\circ} 26842$ - Ley General de Salud (LGS), así como analizar los tres proyectos de ley presentados en los dos últimos meses para modificar ese artículo 7 de la LGS; lo que nos permitirá establecer los criterios bioéticos y biojurídicos para regular las TRA, derogando el artículo 7 de la LGS. Los criterios éticos se enmarcan en la interdisciplinariedad de la bioética, en la búsqueda de un estatuto jurídico del concebido y en los límites éticos que deben regir la ciencia y la tecnología. Los resultados de la investigación apuntan a comprender que el ordenamiento jurídico del Perú es proteccionista del concebido, pero no el artículo 7 de la LGS que autorizó las TRA, por implicar riesgos para la vida y la salud de los seres humanos en estado de embriones. Nuestra investigación aporta criterios bioéticos y biojurídicos para regular las biotecnologías del inicio de la vida, poniendo límites a las TRA, por exigirlo el derecho de los embriones humanos de acuerdo con su estatuto biológico, ontológico y jurídico.

${ }^{1}$ Bachiller en traducción e interpretación de texto por la Universidad Sagrado Corazón - UNIFE. Conductora radial en Radio Maria. Miembro del Directorio de FASTA Perú. Maestra en Persona Matrimonio y Familia. Email: olfertap@hotmail.com. ORCID: https://orcid.org/0000-0002-3770-2466

${ }^{2}$ Abogado por la Universidad Nacional Mayor de San Marcos. Diploma de Estudios avanzados en filosofía política por la Universidad de Barcelona. Maestro en Persona Matrimonio y Familia. Email:scbtapia@hotmail.com. ORCID: https://orcid.org/0000-0001-9641-6171 
Trends in the bills of laws of 2018, to regulate the techniques of artificial reproduction in Peru

\section{ABSTRACT}

\section{Keywords.}

Bioethics

Bio-legal artificial reproduction Techniques (ART)

Biotechnologies

Conception shelter

Human embryo

Pre-embryo

Subrogated maternity

Child-conservation

Embryo selection

Embryo reduction.
The Artificial Production Techniques (APT) generate human life in an artificial way, that is to say without observing the natural process that is the sexual union between male and female. So that, we deem it appropriate to establish bioethics and bio-legal criteria, in the circumstances that the modification of the norm about APT in Peru, will be discussed. For this purpose, with this investigation we analyze the content and consequences of the APT, we analyze the current 7th. article of the General Health Law (GHL), as well as analyze the three bills presented in the last two months to modify article 7 of the GHL; that will allow us to establish the bioethic and bio-legal criteria to regulate the APT abolishing the 7th article of the GHL. The ethic criteria are framed in the interdisciplinary of bioethic, the search for the judicial statute of the conceived and the ethic limits that should rule the science and technology. The results aim to understand that the legal order in Peru is protectionist of the conceived, but not the 7th. article of the GHL authorized by the APT, For involving risks to the life and health of human beings in the state of embryos. Our research provides bioethical and biolegal criteria to regulate the biotechnologies of the beginning of life, putting limits to the TRA, to demand it the the right of human embryos, in accordance with the biological, ontologic and legal statutes.

\section{Introducción}

En el Perú, desde el año 1997, está vigente el artículo $7^{\circ}$ de la Ley $N^{\circ} 26842$ Ley General de Salud (LGS), que legaliza para toda persona poder recurrir al tratamiento de infertilidad y legitima como "derecho" la procreación mediante el uso de TRA.

Esta norma exige la coincidencia en la misma persona de las condiciones de madre genética y madre gestante; requiere el consentimiento previo y por escrito de los padres biológicos, y prohíbe la fecundación de óvulos humanos con fines distintos a la procreación y también prohíbe la clonación de seres humanos. Pero, el texto de la norma se inclina a la ambigüedad y la hace permisiva para la aplicación de las TRA. Dando lugar a que el deseo de cualquier persona, de superar su infertilidad, le permita acceder a las TRA, sin exigir el rol de la institución de la familia, e ignorar que la ley peruana reconoce como niño al ser humano desde la concepción hasta los doce años de edad. Este artículo $7^{\circ}$ de la LGS ha generado servicios de TRA sin ningún "tipo de control de parte del Estado, (...) y las clínicas e institutos de fertilidad siguen funcionando en la más absoluta tranquilidad o, quien sabe, impunidad" (Cárdenas, 2014, p. XIII).

Este artículo $7^{\circ}$ de la LGS, dentro de sus primeros veintiún años de vigencia, ha sido objeto de varios intentos para modificarlo con la 
intención de favorecer aún más la difusión y aplicación de las TRA. Y, recientemente, el Congreso de la República ha recibido tres iniciativas de ley con ese fin. ${ }^{3}$.

Esos proyectos de ley ponen en riesgo la protección jurídica del inicio de la vida humana, la preservación de la verdadera identidad de los embriones y el destino que deparará a los embriones que se califiquen de "sobrantes" para los fines de las TRA.

Las TRA conllevan riesgo de contenido ideológico que las deslegitima. Recurren a la manipulación del lenguaje, al uso de términos de la corrección política como el de maternidad subrogada, así como novedosos conceptos como pre-embrión. También, transubstancian con contenidos diferentes términos ya existentes como familia, filiación y paternidad. Se induce a pensar que aplicar las TRA satisfacen una "necesidad", y transforma "el deseo" de tener un hijo a la categoría de "derecho" a tener un hijo.

Es conveniente establecer los criterios bioéticos y biojurídicos que toda legislación sobre TRA debe presuponer, para brindar el marco fundamental para el respeto de los derechos del embrión. Evidenciando la relación que existe entre la ciencia, la técnica, la antropología y el derecho, cuando se trata de la vida de los seres humanos y sus inalienables derechos. Lo que sirve para elaborar normas y enriquecer la jurisprudencia.

${ }^{3}$ El 7 de setiembre de 2018 fue presentado el Proyecto de Ley $N^{\circ} 3313 / 2018$ CR, el 18 de setiembre se presentó el Proyecto de Ley $N^{\circ}$ 034/2018-CR y el 11 de octubre el Proyecto de Ley $\mathrm{N}^{\circ}$ 03542/2018-CR. Coincidentemente concurren todos en proponer fórmulas para modificar o sustituir la norma contenida en el artículo $7^{\circ}$ de la LGS para ampliar libérrimamente la aplicación de las TRA en la totalidad de sus modos de aplicación y alcances.

4 "El término sobrantes se tomó de la Sentencia del Tribunal Constitucional acerca de la constitucionalidad de la ley 35/88." Zurriaráin, 2007.

\section{Metodología}

La investigación se ciñe a la naturaleza de investigación teórica, y cualitativa, de tipo descriptivo-documental.

Para poder reunir los datos necesarios, hemos recurrido al método de fichaje, y el análisis y comentarios de documentos.

Nuestra investigación enmarca criterios éticos dentro de la interdisciplinariedad de la bioética, con la búsqueda de un estatuto jurídico del concebido

En cuanto a criterios de rigor científico hemos considerado la claridad, credibilidad y profundidad.

\section{Resultados, análisis y discusión}

El sistema legal peruano es protector de la vida humana desde la concepción, como se proclama en el Numeral 1 del artículo 2 de la Constitución Política, así como en el artículo 1 del Código Civil y en los principales instrumentos internacionales sobre derechos humanos ratificados por el Perú que forman parte del derecho peruano ${ }^{5}$. Sin embargo, mediante normas de inferior jerarquía ${ }^{6}$ y por sentencias de

\footnotetext{
5 "Artículo $2^{\circ}$.- Toda persona tiene derecho: 1. A la vida, (...). El concebido es sujeto de derecho en todo cuanto le favorece." CONSTITUCIÓN POLÍTICA DEL PERÚ. "Artículo 1.- Principio de la Persona y de la Vida Humana.- (...) La vida humana comienza con la concepción. El concebido es sujeto de derecho para todo lo que le favorece (...)." CÓDIGO CIVIL. "Artículo 55․- Los tratados celebrados por el Estado y en vigor forman parte del derecho nacional." CONSTITUCIÓN POLÍTICA DEL PERÚ.

${ }^{6}$ RESOLUCIÓN MINISTERIAL N 486-2014/MINSA Aprueban la Guía Técnica Nacional para la estandarización del procedimiento de Atención Integral de la gestante en la Interrupción Voluntaria por Indicación Terapéutica del Embarazo menor de 22 semanas con consentimiento informado en el marco de lo dispuesto en el artículo 119 del Código Penal. [Ubicado el 22.VII2016]. Obtenido en file:///C:/Users/Sergio/Downloads/NL20140628.pdf
} 
tribunales nacionales ${ }^{7}$ como también de la Corte Interamericana de Derechos Humanos (Corte $(\mathrm{IDH})^{8}$, se observa una constante erosión en ese bloque esencial de nuestro sistema jurídico que es protector de la vida humana. Se verifica una persistente desestabilización de las normas defensoras de la vida humana, que debilita la consistencia y la eficacia para la protección de la vida humana en su etapa inicial. En este contexto, se pone de mayor manifiesto la norma legal contenida en el artículo $7^{\circ}$ la $\mathrm{LGS}^{9}$ que tiene como efecto, quizá no previsto por el legislador de hace 21 años, de debilitar la protección de la vida a quien está por nacer, mediante el uso de las TRA.

Frente a ese debilitamiento de la eficacia jurídica del sistema legal nacional, y con miras a nuestro objetivo de establecer los criterios

\footnotetext{
7 La Casación 5003-2007 versa sobre las TRA aplicadas sin cumplir los requisitos establecidos por el art. 7 de la Ley General de Salud, y constituyó el primer caso de TRA conocido por la Corte Suprema, que resolvió en abierto incumplimiento de la ley. En la sentencia recaída en el Expediente $\mathrm{N}^{\circ} 183515-$ 2006-00113, se consideró no ilegal la maternidad subrogada, en franca contradicción con el referido art. 7 de la Ley General de Salud. Y, en la Casación 563-2011-Lima que resuelve diferencias patrimoniales entre personas que participaron como madre genética y madre gestante, que no está admitida por la referida norma de Salud. Ibañez (2014), págs.. 127-140.

8 "264. La Corte ha utilizado los diversos métodos de interpretación, los cuales han llevado a resultados coincidentes en el sentido de que el embrión no puede ser entendido como persona para efectos del artículo 4.1 de la Convención Americana. Asimismo, luego de un análisis de las bases científicas disponibles, la Corte concluyó que la "concepción" en el sentido del artículo 4.1 tiene lugar desde el momento en que el embrión se implanta en el útero, razón por la cual antes de este evento no habría lugar a la aplicación del artículo 4 de la Convención. Además, es posible concluir de las palabras "en general" que la protección del derecho a la vida con arreglo a dicha disposición no es absoluta, sino es gradual e incremental según su desarrollo, debido a que no constituye un deber absoluto e incondicional, sino que implica entender la procedencia de excepciones a la regla general. (...) 315. En contraste, el impacto en la protección del embrión es muy leve, dado que la pérdida embrionaria se presenta tanto en la FIV como en el embarazo natural. La Corte resalta que el embrión, antes de la implantación no está comprendido en los términos del artículo 4 de la Convención y recuerda el principio de protección gradual e incremental de la vida prenatal (supra párr. 264)". (Corte Interamericana de Derechos Humanos, Corte IDH, 2012).

${ }^{9}$ LEY N ${ }^{\circ} 26842$, LGS.
}

bioéticos y biojurídicos necesarios para ser incorporados en la legislación peruana para regular las TRA, abordamos el contenido de las TRA y las consecuencias que acarrean.

\section{Las técnicas de reproducción artificial: contenido y consecuencias}

La primera cuestión es en cuanto a la denominación de las técnicas de reproducción, si son artificiales o deberían completar su denominación como asistidas. Las TRA son procedimientos artificiales, y es un eufemismo agregarle la palabra asistidas. Tales técnicas tienen por objeto sustituir el acto humano procreador, mediante recursos tecnológicos reproductores. Al respecto, explica Ciccone:

\begin{abstract}
Por todas partes se ha impuesto la denominación: Procreación médicamente asistida (...). Pero si se miran despacio las cosas, (...) salvo en el caso de la Inseminación artificial homóloga impropiamente dicha. (...) Todas las demás intervenciones, sin embargo, no ayudan, sino que sustituyen los actos procreativos humanos con procedimientos típicos de un laboratorio de biología, similares en su sustancia a los que se utilizan para la reproducción artificial de los animales. Por esto resulta mucho más apropiado hablar de Técnicas de reproducción artificial o Técnicas reproductivas. (Ciccone, 2006, p.100)
\end{abstract}

\section{Consecuentemente adoptamos la} denominación técnicas de reproducción artificiales, a las que también identificamos mediante la abreviatura TRA. 


\section{Contenido de las técnicas de reproducción artificial}

Las TRA están destinadas a producir fecundación artificial, procrean artificialmente vida humana sin observar el proceso natural que consiste en la unión sexual de un hombre con una mujer (Lucas, 2013, p. 56). Las TRA no constituyen acto médico curativo de la infertilidad ni de la esterilidad, no son complementarias ni coadyuvantes de la procreación humana porque son un sustituto artificial: "Llamamos reproducción artificial a los diversos procedimientos técnicos encaminados a lograr la concepción de un ser humano por una vía diversa de la unión sexual del varón con la mujer". (Elbaba, 2007, p. 147). Hay dos grandes modos de procurar la fecundación de manera artificial: dentro del cuerpo o fuera del cuerpo materno. En el primero, la fecundación intracorpórea, trabaja artificialmente sobre los gametos masculino y femenino, obtenidos por vías distintas al acto sexual, para luego colocarlos en el aparato reproductor femenino y esperar la fertilización. En el segundo, la fecundación extracorpórea, los embriones se producen en el laboratorio, para su posterior transferencia al cuerpo materno.

A mayor abundamiento las tecnologías reproductivas son de fecundación "intracorpórea, si la fecundación se da dentro de las vías genitales femeninas". (Lucas, 2013, p. 57). Las que comprenden dos técnicas:

Inseminación artificial. Se requiere recoger el líquido seminal, independiente al acto conyugal o en conexión con él, siendo la modalidad más utilizada la masturbación. La técnica implica el examen de los espermatozoides para comprobar si reúnen los requisitos que los hacen capaces de fecundar y descartar agentes patógenos. Luego se depositan en los diferentes tramos genitales femeninos, según sea el obstáculo que se deba superar (Ciccone, 2006). Si los espermatozoides pertenecen al marido se denominará homóloga, y será heteróloga si provienen de un tercero.

Transferencia intratubárica de gametos (GIFT). La técnica procede a estimular la producción de óvulos para su extracción del cuerpo femenino. Obtenida la muestra de semen, se examina y selecciona los espermatozoides aptos. Se eligen tres ovocitos y los espermatozoides son colocados con una cánula en las trompas, a la espera que la fertilización ocurra; fertilizado el ovocito, el embrión sigue su proceso normal hasta llegar al útero. La técnica es aplicada a mujeres con endometriosis (Elbaba, 2007).

De otro lado, con respecto al grupo al que pertenecen las tecnologías reproductivas con fecundación extracorpórea, según López e Iraburu (2006) hoy son más usadas las técnicas de "la fecundación invitro con transferencia de embriones (FIVET o FIV) y la inyección intracitoplásmica de espermatozoides (ICSI)" (p. 81). Ambas se caracterizan por producir embriones en el laboratorio, por lo tanto son extracorpóreas, y que luego serán transferidos a la mujer. En palabras de Lucas (2013) "la fecundación ocurre fuera del cuerpo femenino, es decir, en una probeta" (p. 57). Siendo dos las técnicas que comprende este clasificador:

La Fecundación in vitro (FIVET). Una de las técnicas más utilizadas es la fecundación in vitro con transferencia de embriones conocida como FIVET: "al hablar de FIVET pretendemos referirnos no solo a la que puede llamarse su forma clásica, sino a todas aquellas variantes que, aunque (...) con siglas diferentes, comportan fecundación in vitro y la transferencia del embrión a uno u otro tracto del aparato femenino" (Ciccone, 2006, p. 119). Asegurar su 
eficacia exige condiciones muy precisas: los gametos femeninos y masculinos deben activarse mutuamente, y deben estar en condiciones adecuadas de maduración. Para poder realizar la FIVET es necesario realizar la estimulación hormonal de la mujer para obtener los óvulos necesarios, tantos como para lograr varios embriones para transferirlos al útero. Debe repararse que la maduración de los óvulos obtenidos mediante esta técnica acusa deficiencias, que traen como consecuencia la pérdida de embriones por dificultades en la anidación, y por la alta tasa de malformaciones en los embriones (López e Iraburu, 2006).

La otra técnica es la Fecundación Intracitoplásmica (ICSI), que consiste en inyectar con micro-jeringa un solo espermatozoide directamente en el citoplasma del oocito, por lo general se producen varios embriones con esta técnica y luego de 48 a 72 horas los embriones se transfieren a la cavidad uterina. Está indicada en casos de esterilidad masculina (Elbaba, 2007).

El estudio de estas técnicas permite comprobar que acarrean consigo la pérdida de vida de varios embriones, además de otros riesgos que señala la Sociedad Europea de Reproducción Humana y Embriología: "La FIV puede dar lugar a un creciente riesgo de embarazos múltiples, complicaciones durante el embarazo, bajo peso al nacer, taras importantes en el nacido y a largo plazo, discapacidades en los niños que sobrevivan" (Elbaba, 2007, p. 154).

Frente al anhelo de maternidad o paternidad satisfecho mediante las TRA, es pertinente ponderar si producir vida humana de manera artificial, con las consecuencias del alto costo en riesgo y pérdida de vidas humanas en estado embrionario, es ético y justo. Sánchez Abad dice, en primer lugar, que no estamos ante un problema de salud, pues la esterilidad aunque con frecuencia implique un gran sufrimiento no es un problema físico o fisiológico vital, por lo tanto hay que sopesar si es proporcional correr todos los riesgos que implican para la salud del hijo, frente al deseo de maternidad o paternidad (Sánchez, 2012).

Las tasas de éxito de estas técnicas son bajas, al punto que si éstas se dieran en otros tratamientos médicos su eficacia sería considerada como muy pobre. Porque, además de la gran desilusión de muchas parejas al no lograr ser padres, sigue siendo aún mucho más grave la pérdida de muchas vidas humanas (Elbaba, 2007).

Por ello, Pardo señala como "exiguo" (2003) el rendimiento de la técnica, pues para lograr un niño se han empleado un promedio de 24 embriones, en los casos que no hay éxito se emplean tres embriones por cada ciclo, lo que hace que se empleen 15 embriones. En los casos que el matrimonio termine con un hijo y que esto se logre en el tercer ciclo, son 9 los embriones empleados. Comparando con las tasas naturales de éxito sería $4 \%$ de efectividad mediante la técnica, frente a un $25 \%$ a $60 \%$ de éxito en los embarazos naturales: "En los casos menos favorables de FIV, el número de embriones perdidos se multiplica, y la efectividad es de sólo el 1\%" (Pardo, 2003).

Surge, entonces, la siguiente cuestión: ¿Cómo una técnica, que en realidad no es médica ni terapéutica, porque no cura la infertilidad, que es costosa e implica riesgos para la salud de la mujer y del niño a producir, que implica la pérdida de vidas humanas; sin embargo ha alcanzado masivos niveles de difusión nacional e internacional, y goce en el Perú de un marco legal mediante el art. $7^{\circ}$ de la LGS, con todas las consecuencias que implica?

La respuesta hay que encontrarla en el clima culturalmente favorable, trabajado durante 
más de cincuenta años, con la complicidad de los medios de comunicación masiva. Por lo que consideramos con Ciccone (2006) que "es útil conocer ese contexto para comprender mejor los significados más profundos de la aparición y difusión de la TR" (p.129).

Hay dos presupuestos culturales, muy interiorizados en las personas: De un lado, creer que los valores pertenecen al mundo subjetivo y privado de cada quien, y de otro lado, que la ciencia es zona franca carente de valores (Ciccone, 2007). La consecuencia práctica ha llevado al hombre moderno a hacer una dicotomía en su vida, entre su vida privada y su vida pública, profesional, social, o política. En esta postura se advierte el relativismo, pues se pretende omitir la existencia de valores objetivos, y además la vivencia de los valores se reduce al ámbito privado. Esta postura cultural ha favorecido a la difusión masiva del uso de las TRA, porque hay una valoración relativa de la vida humana: Algunos seres humanos valen más que otros, la vida de algunos embriones, los sanos y los aptos, vale más que la de los deficientes; la vida de los embriones implantados vale más que la de los embriones que serán crioconservados; se cuida la vida de los embriones en proceso de gestación y se desprecian, se desechan o experimenta con los otros. Relativizar el embrión es considerarlo sujeto y también objeto; en algunos casos, será sujeto cuando se pretende que sea hijo para darlo a unos padres, pero el costo de considerarlo sujeto exige que a otros embriones se les considere objetos, porque se descartan, se crioconservan o se experimenta con ellos.

Otra característica de este clima cultural es el desarrollo tecnológico y científico ha progresado de manera vertiginosa y el hombre moderno le ha asignado al progreso un valor supremo y casi absoluto, por lo tanto considera que todo lo que es técnicamente posible será éticamente lícito. La biología, la ciencia de la vida, ha dado la sensación de un poder sobre la vida y sobre los embriones humanos, considerados como objeto de investigación científica (Ciccone, 2006).

El vocabulario en este dominio de las ciencias también se ha tornado eufemístico. Se habla de pre-embrión, maternidad subrogada, técnicas de fertilización asistida, reducción embrionaria, embrión preimplantatorio. Terminología que encubre una dramática la consecuencia real contra la dignidad humana en la etapa inicial de la vida.

El soporte ideológico de las TRA, primero induce establecer sus postulados y luego fuerza en acomodar la realidad al esquema del pensamiento ideologizado. Es lo que explica por qué, nuestra sociedad, ha admitido convencida que los embriones no son seres humanos y que "la vida del embrión no equivale a nuestra vida" (Herranz, 2013, p. 6). Y, por su parte, Pardo (2011) sostiene que "estamos inmersos en una cultura donde el hombre es capaz de hacer violencia a la realidad y decir que las cosas no son lo que son" (p. 12).

Frente a este contexto cultural es necesario comprender siguiendo a $D^{\prime}$ Agostino citado en (Zurriaráin, 2007) que "la procreación humana es mucho más que una mera reproducción biológica: es el origen de los vínculos de parentesco, que presuponen un reconocimiento y no engloban en sí mismos meros significados biológicos, sino que adquieren significados y valores estrictamente antropológicos que constituyen el eje de sustentación de la hominización". Tal vez para muchos las consecuencias que las TRA acarrean para la institución familiar no sean tan evidentes ni palpables, como las que hemos señalado para el embrión, sin embargo desde diversas instancias 
se ha denunciado que desnaturalizar la familia equivale a destruirla (Ciccone, 2006).

La familia es el bien común de la humanidad, es una institución natural y universal que responde a la necesidad del varón y de la mujer de establecer un vínculo o unidad en base a la relación afectiva, voluntaria y estable entre ambos, orientada a la procreación, "un institutum, con unos elementos perennes no sometidos al vaivén de los cambios culturales, sociales y económicos" (Miralles, 1980, págs. 152-153). Debilitar a la familia como sociedad natural es algo que desfavorece a la sociedad.

Estos elementos perennes, a través de las TRA, son trastocados según Lucas (2013) “En la fecundación artificial el hijo es agregado o introducido en la familia desde el exterior y en el caso de la fecundación heteróloga, (...)" introduce "a una tercera o cuarta persona" ( $p$. 63). Esta fertilización artificial heteróloga, conocida en la práctica como vientre de alquiler o útero de alquiler, trastorna las reglas de la filiación, con toda razón Lucas (2013) nos dice "un niño-probeta puede (...) tener a tres madres (biológica, portadora y legal) y dos padres (biológico y legal)" (p. 63). La realidad de las TRA con vientre de alquiler, ha superado la ficción. Cada vez con más frecuencia se dan los casos de mujeres extrañas y desconocidas que reciben un pago por ser las gestantes durante nueve meses. Por otro lado, se da el caso de parientes cercanos que llegan a ser al mismo tiempo, madre gestante y abuela o tía del niño concebido. Se dan también combinaciones de padre biológico y tío del bebé. Situaciones todas con implicancias impredecibles en lo físico, psicológico y jurídico.

Lamentablemente es una tendencia extender los servicios de TRA, más allá del ámbito de las parejas estériles. Edwards citado en Ciccone (2006) nos pone en alerta sobre las consecuencias que las TRA pueden significar para la familia: "producirá una revolución en la familia y en el hecho de ser padres". Parafraseando a Edwards citado Ciccone (2006) los parientes serán ficticios, ya no existirá vínculo biológico entre los padres y los hijos, se hablará de padres sociales, otros serán los criadores y otros los biológicos, el concepto de familia se convertirá en un concepto folclórico, las relaciones en la familia ya no serán por parentesco, a lo máximo esas relaciones se podrán llamar de intimidad, el concepto de familia terminará por convertirse en una mera etiqueta de catalogación, que servirá para definir unas relaciones sin que cuenten los vínculos jurídicos y sin que exista ninguna conexión de consanguinidad.

Del mismo modo la donación de gametos, la compra de esperma u óvulos, en bancos especializados y el anonimato de los donantes, altera sin duda alguna la relación paterna y materna filial. Estas consecuencias son de suma importancia considerar para efectos de una probable regulación de las TRA. La investigación realizada por Cárdenas (2014) sobre "El derecho de las personas concebidas mediante técnicas de reproducción asistida a conocer su identidad biológica desde una perspectiva biojurídica" (págs. III y XI-XV), constituye un oportuno aporte para revisar los problemas jurídicos surgidos del anonimato de los donantes de gametos y los conflictos de derechos que acarrea.

Análisis de la norma relacionada a las técnicas de reproducción artificial en el Perú

La cultura jurídica peruana está fuertemente influenciada por el positivismo jurídico, la ley dada por la autoridad se concibe como si fuese el mismo Derecho. En tanto que, la decisión de los magistrados no forma precedente de carácter obligatorio, lo que contribuye a sostener la fuerza y vitalidad de la ley como fuente de todo derecho, con excepción 
de los cambios ideológicos que a veces causa el TC.

En el Perú, con la aprobación del artículo $7^{\circ}$ de la LGS, se legalizó la posibilidad de que toda persona pueda recurrir al tratamiento de su infertilidad, mediante las TRA. El texto legal es el siguiente (LEY $N^{\circ} 26842$, LGS):

"Artículo 7.- Toda persona tiene derecho a recurrir al tratamiento de su infertilidad, así como a procrear mediante el uso de técnicas de reproducción asistida, siempre que la condición de madre genética y de madre gestante recaiga sobre la misma persona. Para la aplicación de técnicas de reproducción asistida, se requiere el consentimiento previo y por escrito de los padres biológicos.

Está prohibida la fecundación de óvulos humanos con fines distintos a la procreación, así como la clonación de seres humanos."

Aunque aparentemente se trataría de una norma restrictiva por:

(i) Exigir la coincidencia en la misma persona de las condiciones de madre genética y madre gestante;

(ii) Requerir el consentimiento previo y por escrito de los padres biológicos;

(iii) Prohibir la fecundación de óvulos humanos con fines distintos a la procreación, y

(iv) Prohibir la clonación de seres humanos.

Sin embargo es una norma que no regula otros aspectos y consecuencias de las TRA, como el estatuto ontológico del concebido, y el estatuto jurídico que corresponde reconocérsele (Lacadena, 2003). Además no establece si las personas infértiles que recurran a las TRA, deban ser casados y conforman una familia estable, que los haga aptos para recibir al concebido de acuerdo a lo que exige su dignidad (Elbaba, 2007). No impone límites al número de embriones producidos e implantados, no prevé el destino de los embriones no implantados ${ }^{10}$. Elude regular la donación de esperma y los bancos de esperma, haciendo referencia solo a los padres biológicos (Sambrizzi, 2001).

La extensa vigencia en el tiempo de esta norma, y su imprecisión, han generado que se brinden servicios de TRA, por instituciones privadas y públicas, sin restricción ni límites de ninguna índole, bajo la falsa proposición de ser lícito todo aquello que la norma legal escrita no prohíbe expresamente. Esta visión produce atentados contra la vida y la salud de los concebidos, en contravención del sistema jurídico imperante.

En los hechos, las pocas restricciones reguladores de esta norma han sido incumplidas por los magistrados del Poder Judicial al resolver los conflictos de intereses patrimoniales que en torno a las TRA se han resuelto mediante sentencias. Además, la norma es incumplida por las clínicas y centros de fertilización con los servicios que publicitan y ofrecen, prácticamente ya se ha constituido todo un mercado de consumidores que libérrimamente demandan servicios de TRA con absoluta impunidad por la inobservancia legal en la que incurren. Por lo que urge la derogación de este artículo $7^{\circ}$ de la Ley General de Salud, y su pronta sustitución normativa mediante una ley específica en materia de TRA.

\footnotetext{
${ }^{10}$ El problema del importante número de embriones sobrantes, como el de los embriones inviables y los embriones cadáver tal como lo distingue la críoconservación, los problemas éticos relativos a ésta, las cifras muy elevadas de embriones congelados, la paradoja de usar o destruir embriones (Agulles y Guillén, 2011).
} 
Los proyectos de ley sobre técnicas de reproducción artificial

Los tres Proyectos de Ley tienen en común la intención de modificar el artículo $7^{\circ}$ de la LGS, para permitir que la madre genética y la madre gestante sean diferentes personas. Asimismo, en ampliar el acceso a toda persona, aunque en cada Proyecto de Ley los requisitos de edad y otras exigencias varían. Ambos tres, incurren en no tener claridad conceptual, y hasta en confundir, la esterilidad con la infertilidad. La primera, es una incapacidad para concebir. La segunda es una incapacidad para concluir con el embarazo ya iniciado, por tanto, los infértiles pueden engendrar, lo que no pueden es concluir todo el proceso de gestación. Por lo que los infértiles no requerirían de aplicación de TRA. Los tres proyectos han sido remitidos a estudio y dictamen a dos comisiones ordinarias del Congreso: la de Salud y Población y la de Justicia y Derechos Humanos, nosotros estimamos que los tres Proyectos de Ley deberían haber sido remitidos con prioridad a la Comisión de Constitución y Reglamento, debido a la complejidad y consecuencias jurídicas de la materia que tratan, que no es un problema de salud, ni es un tema de armonización legislativa, sino un sensible problema que afecta a la persona humana, que es el fin supremo de la sociedad y del estado ${ }^{11}$.Curiosamente, en la pág. 7 de la Exposición de Motivos, se alega para justificar este Proyecto de Ley "los evidentes vacíos legislativos existentes en nuestro ordenamiento jurídico"; más nosotros consideramos que de prosperar esta iniciativa legislativa, se profundizará en nuestro sistema jurídico nacional no sólo vacíos sino contradicciones perjudiciales para la debida observancia del respeto a la dignidad del ser humano en su estado embrionario.

\footnotetext{
11 "Artículo $1^{\circ}$.- La defensa de la persona humana y el respeto de su dignidad son el fin supremo de la sociedad y del Estado" (Constitución Política del Perú).
}

El Proyecto de Ley 03313/2018-CR, tiene por finalidad ofrecer confianza y asegurar para que toda persona mayor de edad acceda integralmente a las técnicas de reproducción humana asistidas que reconozca la Organización Mundial de la Salud (OMS). Como requisito adicional, se exige una certificación médica que acredite que el sujeto sufra algún grado de infertilidad, pero el Proyecto de Ley no discierne ningún criterio para establecer la graduación de las infertilidades. Se intenta que mediante ley se declare la infertilidad como enfermedad, lo que traería como consecuencia la obligatoriedad de aplicar fondos económicos por el estado, el seguro social y los seguros privados, como expresamente se menciona en su artículo $15^{\circ}$; aunque contradictoriamente en la página 17 de la Exposición de Motivos, bajo el subtítulo Análisis Costo-Beneficio se niegue que tal Proyecto irrogará gastos adicionales en el presupuesto del Estado. Para fines de cobertura a cargo del Estado, seguro social y seguros privados, se establece que la mujer no será mayor de 40 años y si los usuarios del servicio sean parejas deberán ser casados o en unión de hecho; la cobertura por el estado y los seguros social y privados será en el caso de baja complejidad hasta para tres intentos de aplicación de TRA por cada año, y para casos de alta complejidad una vez por año. Este instrumento legislativo es permisivo a la donación de embriones, sólo a los centros de salud autorizados, lo que se contrapone al ordenamiento jurídico nacional $^{12}$, pues, se estaría vulnerado la condición de sujeto de derecho al embrión humano, cosificándole al reducirlo como objeto de transacción para transferirlo en propiedad a título de donación. Permite conservar congelados a seres humanos en etapa embrionaria, lo que atenta contra la dignidad de la persona del concebido, e impone plazo de dos

\footnotetext{
${ }^{12}$ El sistema jurídico nacional, sostenido coherentemente por la Constitución y e Código Civil, acoge con efectos jurídicos que el ser humano es tal desde la concepción, y el Código de Niños y Adolescentes en su artículo I define que se es niño desde la concepción.
} 
años expresamente renovables para el cese de la crioconservación de los embriones en estado de congelación. El Proyecto, en el artículo $9^{\circ}$, admite la gestación por sustitución, siempre y cuando el acuerdo sea a título gratuito; el criterio para otorgar la titularidad de la filiación materna es a favor de quien aporta el material genético femenino o por la madre biológica. Este Proyecto contiene una adición al Código Penal, tipificando el delito de intermediación onerosa de embriones y gametos crioconservados.

El proyecto de Ley 03404/2018-CR, es un instrumento parlamentario que carece de acertada técnica de redacción en articulados, lo que es ostensible en sus primeros artículos al señalar el objeto de la ley, al modificar el artículo $7^{\circ}$ de la LGS y al adicionar un artículo en la LGS. El Proyecto declara que ser madre es un derecho humano. No admite la comercialización de embriones y gametos, pero si regula la transferencia en propiedad a título de donación de seres humanos en etapa embrionaria. Restringe la edad de quienes pueden acceder a la aplicación de las TRA, mayores de 24 años y menos de 47 años, y que sean casados o en unión de hecho acreditada. Permite la donación de gametos de terceros si ambos integrantes de la pareja son "infértiles". Para las mujeres que se ofrezcan como gestantes voluntarias, exige la nacionalidad peruana o la residencia legal, ser mayor de 24 años, haber sido madre al menos de un hijo "sano" y poseer situación económica estable sin estar registrada en el Sistema de Focalización de Hogares - SISFHO. El artículo $8^{\circ}$ del Proyecto de Ley expresamente incurre en iniciativa de gasto a cargo del estado, que está expresamente prohibido por el artículo $79^{\circ}$ de la Constitución Política ${ }^{13}$. En cuanto a las reglas de filiación, el artículo $7^{\circ}$ del Proyecto de Ley se distancia para negar lo establecido en el sistema jurídico imperante, otorgando la atribución de

\footnotetext{
13 "Artículo $79^{\circ}$.- Los representantes ante el Congreso no tienen iniciativa para crear ni aumentar gastos públicos..." (Constitución Política del Perú).
}

determinar quiénes serán los padres legales, mediante acuerdo privado celebrado ante notario interviniente del acto, y categóricamente niega que la gestante tenga algún derecho $u$ obligación con respecto al "bebé", sancionando con inadmisibilidad de iure a las demandas por filiación que pudieren interponerse.

Finalmente, el Proyecto de Ley 35042/2018-CR, regula el acceso a las TRA para toda la población al subrayar la custodia de "los derechos reproductivos de los ciudadanos", en consecuencia el llamado para la aplicación de las TRA, en esta iniciativa legislativa, es lo más ampliamente universal. El instrumento parlamentario es tolerante con todas las formas de aplicación de las TRA, con el concurso o intervención de terceros, para los efectos de crear vida humana. En el artículo 3.5 del Proyecto de Ley, se restringe el uso de embriones y se prohíbe la fecundación de óvulos, con finalidad diferente a la de procreación humana. Este Proyecto llega a enumerar hasta diez principios generales para la aplicación de la ley que se propone, los que se contradicen con las partes dispositivas del mismo Proyecto de Ley, como declamar sobre el Principio del Interés Superior del Niño, en contraste con la liberalidad de aprobar la manipulación de embriones. Otra previsión consecuencial, señalada en el artículo 5.3 del Proyecto de Ley ${ }^{14}$, la encontramos contradictoria con la liberalidad de la promoción de las TRA que genera el mismo Proyecto. En el artículo $11^{\circ}$ de este instrumento parlamentario se desarrolla la concepción jurídica sobre la donación de gametos y embriones, y en el artículo $12^{\circ}$ la crioconservacion de embriones, ambas operaciones introducen el reduccionismo que atenta contra el valor y la dignidad del ser humano en su etapa embrionaria. Institucionaliza la sustitución de la madre

\footnotetext{
14 “Artículo 5.- Tratamientos de Reproducción Humana Asistida. (...) 5.3. Sólo se aplican las técnicas de reproducción humana asistida que no atenten contra la vida y la dignidad humana" (Proyecto de Ley Nº3542/2018-CR).
} 
mediante el uso del vientre de otra mujer, que eufemísticamente denomina "uso solidario del vientre". Regula los problemas jurídicos sobre filiación, surgidos por la artificiosa manera de engendrar mediante un tercero, desarrollado elucubraciones en un extenso artículo $15^{\circ}$ del Proyecto. En el artículo $19^{\circ}$ autoriza expresamente la investigación sobre gametos y embriones, afectando la vida humana en etapa embrionaria.

Criterios bioéticos para otorgar base científica al ordenamiento jurídico

Los criterios bioéticos que hemos identificado, sobre la vida del embrión humano y su dignidad, para protegerlo y velar por su respeto, son:

A) El valor absoluto de la vida humana y su inviolabilidad. Para Ciccone (2006) tener valor absoluto significa poseer una cualidad inherente que no admite excepción alguna para dejar de respetarla: "El carácter absoluto significa que no está ligado a ninguna condición de edad, grado o desarrollo y a ninguna cualidad de eficiencia, integridad, vigor" (p. 53). Para comprender este criterio es fundamental primero establecer quién es un hombre, cuándo empieza la vida humana y porqué su vida es inviolable. La vida es el bien máximo del hombre "es decir, que es éticamente inadmisible cualquier acto que disponga directamente de una vida humana, tanto propia como de los demás" (Ciccone, 2006, p. 51). El respeto de la vida desde la concepción es el fundamento del respeto de los demás derechos humanos. Esta verdad tan obvia, sin embargo, queda obscurecida por las diferentes teorías que pretenden afirmar que la vida no empieza con la concepción sino en otro momento, son posturas que justifican la manipulación o la eliminación de vidas humanas, en abierta violación a este principio.
B) La existencia de certeza entre vida, verdad y libertad. Toda elección, para que sea libre, implica el conocimiento verdadero de la materia objeto de elección. Respecto de la vida de la persona humana, es imprescindible conocer la verdad sobre la vida, qué es, cuándo empieza la vida de la persona humana, quién es la persona, quién es el embrión.

Para Lucas (2013) "la vida, la verdad y la libertad son bienes inseparables, eslabones de una misma cadena: cuando se rompe uno, también se acaba violando el otro. (...) Separar la libertad de la verdad objetiva hace imposible la fundamentación de los derechos de la persona sobre una sólida base racional y establece las premisas de comportamientos arbitrarios y totalitarios, tanto de los individuos como de las instituciones" (págs. 31-32).

Cuando se afirma que la vida no empieza en la concepción sino en la anidación, para permitir mediante las TRA la manipulación de los embriones de menos de 14 días de concebido, o cuando se les dice a las gestantes que ese embrión de menos de 14 días, es un cúmulo de células y que eliminarlo no es un aborto, se comprueba que no hubo verdad en la información, por lo tanto no hubo libertad en la elección que se adoptó. Toda política pública que atente contra la vida del concebido, negando su condición de ser humano o de persona, se basa en la negación de una verdad.

C) El embrión humano es un individuo de la especie humana. El embrión es un ser humano personal y real, no es un ser humano en potencia (Lucas, 1999), Sgreccia (2009) resume dos características que definen al embrión: la especie a la que pertenece y su carácter individual: "Desde un punto de vista científico, el embrión es hombre, porque el óvulo fertilizado contiene un nuevo programa de vida, trazado e inscrito de manera estable en el cigoto. (...). El estudio 
biológico nos demuestra que el embrión no es un mero racimo de células, sino un individuo de la especie humana, identificado por su patrimonio genético, que contiene un proyecto de vida único e irrepetible" (p. 600). El momento inicial de la vida se verifica con la formación del cigoto, que posee dos características: la unicidad y la unidad. Por ser único e irrepetible y un solo ser. Posee identidad genética, e individualización genética y ética. Para la perspectiva embriológica, nacerá cuando se finalice el desarrollo embrionario. Desde la consideración ontológica, el cigoto tiene suficiencia constitucional, es un ser (Zurriaráin, 2007).

La identidad y unidad en el ser no cambian con las etapas del desarrollo humano, el ser humano es un continuum. Los cambios en el proceso biológico no añaden nada a la sustancia del ser, no deben confundirse los accidentes con la sustancia. "El desarrollo de este organismo individual remite a la cuestión filosófica del cambio en los seres corpóreos, esto es, la permanencia de la identidad y unidad de un ser individual organizado a través de los continuos cambios que se dan en él" (Zurriaráin, 2007, p. 77). El embrión es consecuentemente un ser individual, perteneciente a la especie humana, que se inició con la concepción (la unión del óvulo y espermatozoide) y culmina con la muerte.

D) El estatuto ontológico del embrión. La biología pone en evidencia que el embrión es un individuo de la especie humana; la antropología y la metafísica definen al embrión como persona humana y muestran su estatuto ontológico. En este campo se da una confrontación de ideas, por un lado los que postulan que todo individuo de la especie humana es persona y que el individuo se origina desde la concepción $y$, de otro lado, quienes afirman que se empieza a ser persona en otro momento del desarrollo embrionario o a partir de la aparición de ciertas funciones que humanizan.

Todo individuo de la especie humana es persona, porque surge de la naturaleza y origen del ser humano, Pessina en Sgreccia (2009), dice que "ser humano es aquel que nace de otros seres humanos [...] hombre es, de cualquier forma y siempre, aquel que nace de otros hombres".

Es importante dejar claro el tema ontológico sobre el embrión, Palazzani citado en Ciccone (2006), asegura que: “El ser humano "es" persona en virtud de su naturaleza racional, no se convierte en persona debido al efectivo ejercicio de determinadas funciones (...) ser persona pertenece al orden ontológico: la posesión de un estatuto sustancial personal no se puede adquirir ni disminuir gradualmente, sino que es una condición radical. (...) La consecuencia es que el cigoto, el embrión, el feto (lo mismo que el recién nacido o el menor) son "ya" personas. (...)".

Estamos como dice Tomás (2011) ante alguien, "el embrión no puede tener ninguna obligación como sujeto. (...) el embrión solo tiene derechos, no deberes. Son los demás los que tienen deberes hacia el embrión, empezando por el respeto de sus derechos. (...) El primero de esos derechos es, como para todo ser humano, el derecho a la vida (...)" (Ciccone, 2006, p. 85).

Por lo que, apoyados en Sgreccia (2009) afirmamos que: "Desde el punto de vista filosófico, el embrión es persona porque su principio vital es el mismo que el del hombre adulto. Este principio vital no es de naturaleza biológica, sino espiritual. Es un principio inmaterial, que en la tradición de occidente se ha llamado alma" (p. 600). 
E) La dignidad del embrión humano. Sobre el embrión se sostienen dos evidencias fundamentales, por un lado su carácter de individuo de la especie humana, es un ser humano, y por otro lado la naturaleza de su ser tiene la condición de persona. En virtud de ello el embrión humano tiene dignidad. Siguiendo a Aparisi (2013), la dignidad es base y fundamento de los derechos humanos. En este sentido, Lafferriere (2011) al hablar sobre la dignidad humana señala que esta "se funda en que la persona vale en sí misma y no en tanto porque posee ciertas cualidades o sirve para ciertos fines" (p. 147).

Lamentablemente esta verdad no es aceptada actualmente, por haber surgido otras perspectivas y definiciones sobre la dignidad de la persona humana, de las que resultan grandes distorsiones. Es el caso de algunos representantes del enfoque personista o dualista como Parfit, Singer o Enherhardt, quienes niegan "derechos a los seres no racionales, o no autónomos, de la especie homo sapiens, como los embriones, fetos, niños pequeños, deficientes, personas en coma o descerebrados" (Aparisi, 2013, p. 210). Otra perspectiva es la utilitarista que centra su concepción de 'dignidad humana' en el principio de 'calidad de vida' (Aparisi, 2013).

Sumado a estas perspectivas, existen otras posturas que reconocen en el embrión la existencia de un ser humano pero le niegan el carácter personal, posponiéndolo a fases posteriores de la fecundación ${ }^{15}$.

\footnotetext{
15 Para ello distinguen tres momentos de ese desarrollo biológico del embrión, el primero sería desde la fecundación hasta la implantación, lo que abarca las dos primeras semanas, el segundo período sería hacia el día 18 en que se da la formación de la estructura inicial del sistema nervioso, y el tercero cuando se terminan de formar los órganos entre la $8^{\circ}$ a $10^{\circ}$ semanas. Estos consideran que cada estadio le da al embrión una cualificación moral diferente, por lo tanto de acuerdo a su grado de desarrollo surgirán las obligaciones morales $y$, por ende, también las jurídicas, considerando también la dignidad como un atributo gradual, según el grado de desarrollo.
}

"Para unos, el valor del embrión humano no está en el hecho de su hipotética dignidad intrínseca u ontológica" (Aparisi, 2013, p. 5), sino que el deseo de los padres de tener un hijo es lo que daría valor al hijo.

F) Las TRA no solucionan la infertilidad. Otro criterio bioético es que las TRA no son actos médicos terapéuticos, no reparan el funcionamiento de los órganos de la reproducción humana. El infértil seguirá siéndolo, después de habérsele aplicado las TRA, y las TRA se aplican indiferentemente a los fértiles también (Politi, 2010). Tomás (2011) nos dice al respecto: “Tampoco se pueden considerar métodos terapéuticos, puesto que lo que se pretende (...) no es curar, sino sustituir o asistir a un proceso generativo" (p. 76). Por otro lado Aparisi (2012) sostiene que la infecundidad se presenta siempre como una enfermedad, cuando la realidad no lo es, existen muchas causas de la infertilidad tanto en mujeres como en varones, algunas conocidas y otras desconocidas.

Aun en los casos en que la infecundidad tenga un origen patológico conocido "las técnicas de fecundación in vitro, nunca son un terapia. La técnica no pretende, en ningún caso, curar. (...) La mujer sometida a los procesos de fecundación in vitro que tenga una patología previa quedará, de ese modo tan enferma como estaba" Aparisi, 2012, p. 281).

G) Inexistencia del pre-embrión. Es evidente que en "los últimos cincuenta años, se ha pretendido debilitar el estatus ético del embrión humano de pocos días" (Herranz, 2013, p. 5) y se ha introducido una imagen inauténtica con fines utilitarios, para promover el uso general de los métodos anticonceptivos y la difusión masiva de las TRA. También se han desarrollado diversas teorías en torno al inicio de la vida, con la intención de establecer que hay seres humanos que carecen del estatuto 
ontológico de persona, o que este estatus lo adquieren en algún momento de su desarrollo evolutivo. Del mismo modo, se ha pretendido introducir cambios en el lenguaje como con el término pre-embrión.

La embriología ha probado, sin dejar duda alguna, que el proceso de la vida humana tiene su instante inicial con el embrión, y que no es fiable la versión de la existencia del pre-embrión (Gonzales, 2013). Aun así contando con esta evidencia científica sobre la concepción (unión de los gametos femenino y masculino) como el inicio de la vida humana, sin embargo ha surgido en los últimos tiempos el término preembrión, para referirse al embrión en sus primeros 14 días, como simple cúmulo de células, con la intención de negar al embrión humano el estatus biológico de individuo de la especie humana, el estatus ontológico de persona y consecuentemente el estatus jurídico.

El término pre-embrión fue introducido por intereses no científicos y es empleado por los operadores de las TRA como lo demuestra la información brindada por sus propias fuentes ${ }^{16}$. Este término fue introducido por la bióloga McLaren, miembro del Comité Warnock, para referirse al período de desarrollo que va desde el cigoto hasta el día 14. Se fijó ese día de manera arbitraria, para significar que, en el momento de la anidación, cuando el ser engendrado es viable, recién desde ese día 14 allí podría hablarse del inicio de la vida humana. Ella misma luego reconoció que lo hizo por presión ajena a la comunidad científica, a pesar de conocer que el desarrollo del embrión humano es continuo (Zurriaráin, 2007). La finalidad por la cual se ha inventado el término y sigue vigente, es negarle el "carácter individual y personal del embrión humano con el fin utilitarista de justificar su uso

\footnotetext{
16 "La transferencia de pre-embriones es un procedimiento ambulatorio que se realiza en la sala de transferencia embrionaria, sin necesidad de anestesia. Consiste en depositar los pre-embriones en el interior de la cavidad uterina" (Nascentis Especialistas en Fertilidad. La Fertilización In Vitro).
}

como material genético" (Zurriaráin, 2007, págs. 176-177).

Criterios biojurídicos para sustentar el fundamento normativo

La bioética no sólo forma parte del lenguaje jurídico, sino que ya es reconocida y promovida internacionalmente por el derecho internacional público, como se constata del Preámbulo de la Declaración Universal sobre Bioética y Derechos Humanos aprobada por la UNESCO en el año $2005^{17}$. Para González (2006) hay cuestiones bioéticas que en razón de su "eficacia y exigibilidad" (p. 104) deben constituirse en fórmulas jurídicas, porque el desarrollo científico y técnico aplicado a la vida humana genera indudable impacto ético y jurídico, como bien lo reconoce la referida Declaración Universal sobre Bioética y Derechos Humanos ${ }^{18}$. Sin embargo, siendo distante del positivismo jurídico en la precisión señalada por González (2006) ${ }^{19}$, agrega Lafferriere (2011) que es en la necesidad de la regulación jurídica donde "confluyen el Derecho y la Bioética" ( $p$. 240). Precisándose que el bioderecho señala: "lo propio de la tarea jurídica será establecer qué es lo justo, lo debido al otro" (Lafferriere, 2011, p. 242).

\footnotetext{
17 " Considerando que la UNESCO ha de desempeñar un papel en la definición de principios universales basados en valores éticos comunes que orienten los adelantos científicos y el desarrollo tecnológico (...), y que las cuestiones de bioética, que forzosamente tienen una dimensión internacional, se deben tratar como un todo, basándose en los principios ya establecidos en la Declaración Universal sobre el Genoma Humano y los Derechos Humanos y la Declaración Internacional sobre los Datos Genéticos Humanos, y teniendo en cuenta no sólo el contexto científico actual, sino también su evolución futura" (Unesco, 2005)

18 "Teniendo en cuenta los rápidos adelantos de la ciencia y la tecnología, que afectan cada vez más a nuestra concepción de la vida y a la vida propiamente dicha, y que han traído consigo una fuerte demanda para que se dé una respuesta universal a los problemas éticos que plantean esos adelantos" (Unesco, 2005)

19 "... no debemos reducir Derecho a legislación, pues, en su sentido primario, Derecho es la misma cosa justa, lo debido a otro según cierta regla o título. Son también jurídicas, por tanto, las cuestiones de la Biomedicina, y aun las de la Biotecnociencia, en tanto se verifican relaciones de alteridad en que es necesario determinar "lo justo". Es aproximación a la noción de Derecho nos aparta de una visión positivista y nos coloca en un horizonte mucho más amplio que, fundado en la existencia de un núcleo de indisponibilidad al que denominamos ley natural, brinda un fundamento "fuerte" al razonamiento práctico que apunta orientar las conductas humanas" (González, 2006, págs. 244-245).
} 
Los criterios biojurídicos que deben tenerse en cuenta, son:

- El derecho a la vida es el primer derecho.

- Inexistencia del derecho al hijo.

- La dignidad humana como fundamento de todos los derechos.

- Derecho a conocer nuestra identidad.

- El derecho del embrión de nacer en una familia (Helfer y Tapia, 2016).

\section{Conclusiones}

1. Es fundamental el conocimiento del embrión humano desde la biología, la filosofía y el derecho para comprender las TRA y prever sus consecuencias. Las TRA, no se reducen a técnicas surgidas del desarrollo científico, requieren ser comprendidas desde las interdisciplinariedad de la bioética, para juzgar su moralidad, porque sus acciones tienen que ver con la persona humana, la vida humana, la familia y su entorno.

2. Las TRA no constituyen en sí mismas un acto médico terapéutico; pues, no curan la dolencia de la pareja infértil, no tienen propiedades terapéuticas, no remedian la infertilidad por medios quirúrgicos ni mediante fármacos. Antes bien involucran a un tercero (el hijo en estado embrionario), para quien se ignora el principio de beneficencia (tampoco es terapéutico para el embrión), pues mediante las TRA, su vida y salud están en riesgo, y es tratado como producto de laboratorio, vulnerando su dignidad de persona. Pero además, las TRA aseguran su eficacia mediante la producción de embriones humanos, supernumerarios, sin destino cierto, a quienes someten a la crioconservación por tiempo indefinido. En consecuencia, consideramos necesario establecer límites a las TRA, mediante una norma legal, en virtud del mandato constitucional que defiende a la persona humana y el respeto de su dignidad por ser fin supremo de la sociedad y del estado.

3. Las TRA no pueden servir de instrumento para obtener el goce del inexistente derecho al deseo de tener un hijo, no es razón suficiente para legislar su uso y aplicación. La rápida difusión de las TRA, puede tener explicación aunque no justificación, en la inclinación y anhelo de paternidad y maternidad, pero hay también un trasfondo cultural e ideológico innegable, trabajado por diferentes agentes, entre los que no puede descartarse aquellos que buscan el beneficio de ganancias económicas significativas mediante las aplicaciones de TRA.

4. Las TRA, originan una visión egocéntrica e irresponsable sobre la nueva vida humana lograda artificialmente. El hijo es considerado como producto a la carta, objeto de propiedad, sin destino cierto. Las TRA generan una comprensión relativista de la realidad, en la medida que la vida de unos (la de los embriones implantados) vale más que la de otros (la de los embriones crioconservados). Las TRA también tergiversan la comprensión de la realidad, mediante la creación de términos como preembrión, maternidad subrogada, reducción embrionaria, selección embrionaria, que constituyen eufemismos para ocultar las verdaderas implicancias y significados de estas técnicas.

5. El primer criterio biojurídico es el respeto a la vida del ser humano, en cualquiera de las fases de su desarrollo biológico, y a partir del instante mismo de la concepción. La vida es el primer derecho, porque de él fluyen y tienen sostén los demás derechos de la persona humana. El derecho a la vida es de reconocimiento internacional. Este criterio biojurídico tiene el respaldo de las leyes de mayor jerarquía del sistema legislativo peruano: 
la CPP mediante el numeral 1 del artículo 2, el CC por el artículo 1, el CP en los artículos 114 a 120 sobre aborto y en el artículo 124-A sobre lesiones al concebido, y en el CNA en el artículo 1. En el estatuto del embrión humano sostenido en esta investigación, al embrión le corresponden los mismos derechos de su especie humana. Sin embargo, es necesario superar el conflicto de normas que se suscita por la vigencia del artículo 7 de la LGS que autorizó las TRA desde 1997. Habiéndose agregado otras incoherencias $y$ contradicciones en nuestro sistema jurídico, que atentan y debilitan la defensa de la vida humana del no nacido y el respeto a su dignidad, como el Protocolo para el aborto terapéutico aprobado mediante una norma de inferior jerarquía como es la Resolución Ministerial N 486-2014/MINSA, y las decisiones jurisprudenciales de la Corte Interamericana de Derechos Humanos en el Caso Artavia Murillo vs. Costa Rica, y de los órganos del Poder Judicial peruano como la Sentencia $\mathrm{N}^{\circ}$ 183515-2006-00113 del $15^{\circ}$ Juzgado de Familia de Lima, la Casación N N 5003-2007-Lima de la Sala Civil Permanente de la Corte Suprema, la Casación $\mathrm{N}^{\circ}$ 4323-2010-Lima de la Sala Civil Permanente de la Corte Suprema y la Casación № 563-2011-Lima de la Sala Civil Permanente de la Corte Suprema.

6. Es necesario derogar el artículo $7^{\circ}$ de la LGS, mediante la dación de una norma sustitutoria, con la finalidad de regular las TRA en coherencia con la realidad de la vida humana presente en la fecundación artificial y en compatibilidad con el ordenamiento jurídico peruano constitucional y legal. En los hechos, el marco legal contenido en el artículo $7^{\circ}$ de la LGS, ha sido rebasado, tanto que el Poder Judicial ha emitido fallos desconociendo el mandato legal contenido en el referido artículo $7^{\circ}$ de la LGS.

7. Como consecuencia de la difusión de las TRA en el Perú, se requiere una regulación mediante una ley específica que las ilegalice, incorporando sanciones penales para las conductas antijurídicas. Por cuanto se requiere reformular la protección jurídica de la vida y la dignidad de la persona humana en estado de embrión, para que no sea vana la proclamación de la persona como fin supremo de la sociedad y del Estado, contenida en el artículo 1 de la CPP.

8. La crioconservación es un problema de hecho no autorizado por el art. 7 de la LGS, por lo que no debería existir, su solución requiere con urgencia una ley que contenga una regulación que, además de disponer el cese de la producción de embriones para crioconservarlos, resuelva otra grave consecuencia como es la existencia de embriones en crioconservación en clínicas que prestan servicios de TRA

\section{Recomendaciones}

Como estudios complementarios sobre las TRA, es recomendable promover investigación sobre sus consecuencias en la sexualidad matrimonial y en la conformación institucional de la familia, con el objeto de explorar y proponer soluciones de orden bioético, psicológico, educacionales y jurídicas. Especial énfasis debería recaer en la relación paternomaterno-filial en los ámbitos ético, psicológico y jurídico, con vistas a proponer modificaciones en el Código Civil para regular las relaciones jurídicas de parentesco surgidas por aplicación de la fecundación artificial carente de regulación desde 1997. Con tal fin, será útil convenir con el Poder Judicial, un estudio sobre las sentencias y resoluciones dictadas a nivel nacional, en procesos judiciales que hayan conocido y resuelto casos de filiación en materia de fecundación artificial. Asimismo, en las actuales condiciones culturales para la adopción de toma 
decisiones, resulta conveniente promover investigaciones en materia de biopolítica.

\section{Bibliografía}

\section{Libros y artículos de revistas:}

Agulles, P. y Guillén, M. (2011). Ética de la investigación biomédica. Trasplantes, vacunas y embriones. Valencia, España: Edicep.

Aparisi, A. (2012). Implicaciones para el derecho a la vida y a la salud de las nuevas tecnologías reproductivas. En R.G. Zurriaráin. (Ed.), La desprotección del no nacido en el siglo XXI (267-291). Madrid, España: Ediciones Internacionales Universitarias.

Ciccone, L. (2006). Bioética. Historia. Principios. Cuestiones. Madrid, España: Colección Pelícano, Ediciones Palabra.

Cozzoli, M. (1998). Lémbrione umano: aspetti etico-normativi, 237-273. En Pontificia Academia pro Vita, Identitá e statuto dell'embrione umano, Cittá del Vaticano, Vaticano: Librería Editrice Vaticana (citado en Ciccone 2006, p. 85).

Edwards, J. N., New Conceptions: Biosocial Innovations and the Family. En Journal of Marriage and the Family, 1991, mayo, 53, 2, 349-360 (citado en Ciccone 2006, p. 144).

Elbaba, J. (2007). Reproducción Artificial. En Colección AquinasNET Universidad FASTA Bioética (147-163). Mar del Plata, Argentina: Editorial Martín.

González, L. (2006). De la Bioética... al Bioderecho. Libertad, Vida y Muerte. Madrid, España: Universidad Pontificia de Comillas.
Herranz, G. (2013). El embrión ficticio. Historia de un mito biológico. Madrid, España: Ediciones Palabra.

Lacadena, J.R. (2003) Genética y bioética. Madrid, España: Editorial Desclée De Brouwer S.A.

Laferriere, J. N. (2011). Las implicaciones jurídicas del diagnóstico prenatal: El concebido como hijo y paciente. Buenos Aires, Argentina: EDUCA.

López, N. e Iraburu, M. (2006) Los quince primeros días de una vida humana. Pamplona, España: EUNSA.

Lucas, R. (1999) ¿Cuándo se inicia la persona humana? Individualidad biológica y existencia personal. En López, M. y R. Lucas (Ed.) El Inicio de la vida. Identidad y estatuto del embrión humano (59-92). Madrid, España: BAC.

Lucas, R. (2013). Explícame la bioética. Guía explicativa de los temas más controvertidos sobre la vida humana. Madrid, España: Ediciones Palabra.

Palazzani, L. I significati del concetto filosófico di persona e implicazioni nel dibattito bioético e biogiuridico attuale sullo statuto dell'embrione umano. In Pontificia Academia pro Vita (o. c.), p. 73 y ss (citado en Ciccone, 2006, p. 84).

Pardo, J. M. (2011). El no nacido como paciente. Pamplona, España: EUNSA,

Pessina, A. Bioetica. L'uomo sperimentale (citado en Sgreccia, 2009, p.146). 
Sambrizzi, E. A. (2001). La procreación asistida y la manipulación del embrión humano. Buenos Aires, Argentina: Abeledo-Perrot.

Sánchez, P. (2012). Carencias de la comunicación biológica en las técnicas de reproducción asistida (TRA). En R. G. Zurriaráin. (Ed.). La desprotección del no nacido en el siglo XXI (83-88), Madrid, España: Ediciones Internacionales Universitarias.

Sgreccia, E. (2009). Manual de Bioética, Tomo I. Madrid, España: B.A.C.

Tomás, G. M. (2011). Cuestiones actuales de bioética. Pamplona, España: EUNSA.

Zurriaráin, R. G. (2007). Los embriones humanos congelados. Un desafío para la bioética. Madrid, España: Ediciones Internacionales Universitarias.

Tesis:

Cárdenas, A. (2014). El derecho de las personas concebidas mediante técnicas de reproducción asistida a conocer su identidad biológica desde una perspectiva biojurídica (tesis de maestría), Universidad Católica Santo Toribio de Mogrovejo, Chiclayo, Perú.

Gonzáles, R. P. (2013). Límites biojurídicos de la libertad de investigación respecto a la manipulación genética en la vida prenatal (Tesis de pregrado). Universidad Católica Santo Toribio de Mogrovejo, Chiclayo, Perú.

Ibañez, N. (2014) Reflexiones en torno a la jurisprudencia peruana respecto a las técnicas de reproducción asistida (tesis de pregrado), Universidad Católica Santo Toribio de Mogrovejo, Chiclayo, Perú.
Politi, M. B. (2010). Protección jurídica del concebido en el derecho peruano ante la regulación de las técnicas de reproducción asistida (Tesis de pregrado). Universidad Católica Santo Toribio de Mogrovejo, Chiclayo, Perú.

Helfer, O.M. y Tapia, S. C. B. (2016) Incorporación de criterios bioéticos y biojurídicos, ante la probable modificación de la norma sobre técnicas de reproducción artificial (Tesis de maestría). Universidad Católica Santo Toribio de Mogrovejo, Chiclayo, Perú.

\section{Legislación:}

\section{Código Civil.}

Constitución Política del Perú.

Convención Americana sobre Derechos Humanos.

Unesco (2005). Declaración Universal sobre Bioética y Derechos Humanos.

Ley $\mathrm{N}^{\circ}$ 26842, Ley General de Salud (20 de julio de 1997), Diario Oficial El Peruano, Normas Legales 151245-151252 Recuperado de http://www4.congreso.gob.pe/ntley/lmagene s/Leyes/26842.pdf

Resolución Ministerial No 486-2014/MINSA, del Aprueban la Guía Técnica Nacional para la estandarización del procedimiento de Atención Integral de la gestante en la Interrupción Voluntaria por Indicación Terapéutica del Embarazo menor de 22 semanas con consentimiento informado en el marco de lo dispuesto en el artículo 119 del Código Penal. [Ubicado el 22.VII2016]. Obtenido 
file:///C:/Users/Sergio/Downloads/NL2014062 8.pdf

\section{Linkografía:}

Aparisi, A. (2013, febrero) El principio de la dignidad humana como fundamento de un bioderecho global. Cuadernos de Bioética XXIV Recuperado de: http://www.aebioetica.org/revistas/2013/24/8 1/201.pdf

Corte Interamericana de Derechos Humanos (2012). Caso Artavia Murillo y otros (Fertilización in vitro) Vs. Costa Rica. Recuperado de http://www.corteidh.or.cr/docs/casos/articulo s/seriec_257_esp.pdf

Miralles, A. (1980). Naturaleza y Sacramento en la doctrina del Concilio Vaticano II sobre el matrimonio. En Cuestiones fundamentales sobre matrimonio y familia, Pamplona, España, EUNSA, (149-168). Recuperado de http://www.collationes.org/de-vitachristiana/matrimonio-et-familia/item/1817naturaleza-y-sacramento-en-la-doctrina-delconcilio-vaticano-ii-sobre-el-matrimonio.
Nascentis Especialistas en Fertilidad. La Fertilización InVitro. Córdoba, Argentina. Nascentis. Recuperado de http://www.nascentis.com/cmo_es_un_trata miento_de_fertilizacin in_vitro_con_donacin de vulos.

Pardo, A. (2003). La fecundación in vitro. Recuperado de http://www.unav.es/cdb/dhbapfivet.html

Proyecto de ley $\mathrm{N}^{\circ} 3313 / 2018-\mathrm{CR}$, ingresado al Congreso de la República el 7 de setiembre de 2018. Recuperado de: http://www.congreso.gob.pe/pley-2016$\underline{2021}$

Proyecto de ley $\mathrm{N}^{\circ}$ 03404/2018-CR, ingresado al Congreso de la República el 18 de setiembre de 2018. Recuperado de: http://www.congreso.gob.pe/pley-20162021

Proyecto de ley $\mathrm{N}^{\circ}$ 03542/2018-CR, ingresado al Congreso de la República el 11 de octubre del 2018. Recuperado de: http://www.congreso.gob.pe/pley-2016$\underline{2021}$ 